\title{
SCIDiC
}

\author{
International Journal of Dentistry and Oral Science (IJDOS) \\ ISSN: 2377-8075
}

\section{Prevalence of Carpal Tunnel Syndrome Symptoms Among Dentists in Benghazi City - Libya}

Research Article

\section{Abdelmonem Ali Abdelnabi ${ }^{1 *}$, Rafeeq Mohammed Al Kuwafi², Khadeejah Abdulsalam Hashim³ ${ }^{3}$ Marwa Ahmed Bugedar ${ }^{4}$}

${ }^{1}$ Assistant lecturer at Preventive and community dentistry Department, Head of child dental care department at Libyan International Medical University, Libya.

${ }^{2}$ German Board Of Oral And Maxillofacial Surgery, Doctoral Degree By LBMS, Lecturer at Oral and maxillofacial department, Vice Dean at Libyan International Medical University, Libya.

${ }^{3}$ General Dental Practitioner at Libyan International Medical University, Libya.

${ }^{4}$ General Dental Practitioner at Libyan International Medical University, Libya.

\section{Abstract}

Introduction: Many diseases may affect the nerves of a wrist. One of them is Carpal Tunnel Syndrome (CTS). It is defined as "A painful disorder in the wrist and a hand that is caused by compression of the median nerve within the carpal tunnel of the wrist". In the general population the frequency of CTS prevalence ranged between $3 \%$ and $6 \%$.

Objectives: To demonstrate the prevalence of CTS symptoms among dentists who working in Benghazi city -Libya.

Methods: A cross sectional study conducted in Benghazi - Libya in 2019. 205 dentists worked in 14 deferent dental clinics across the city were included. They were required to fill in a questionnaire regarding the symptoms of CTS.

Results:Out of 205 questionnaires were distributed, only 132dentists $(64.4 \%)$ were responded. Of those 132 dentists, 73 were male $(55.3 \%)$ and $59(44.7 \%)$ were female. The results of the study shows that 32 dentists $(24.2 \%)$ of the total participating experienced hand or wrist pain has been at night, whereas 42 dentists $(31.8 \%)$ complained about hand or wrist pain at daytime. In addition, 19 dentists $(14.4 \%)$ of them felt hand numbness and $34(25.8 \%)$ suffered from hand weakness during work. Moreover, hand tingling problems were observed in 23 dentists (17.4\%), and the difficulty with grasping and using small objects were reported in 19 dentists $(14.4 \%)$. Finally, the difficulty of handling manual devices and surgical forceps was detected in 12 dentists $(9.1 \%)$ and 37 dentists (28\%) respectively.

Conclusion: This study shows a significant number of dentists who have symptoms of Carpal Tunnel Syndrome.

Abbreviations: CTS: Carpel Tunnel Syndrome; GDP: General Dental Practitioners.

\section{Introduction}

One of the most common peripheral neuropathy of the median nerve is carpel tunnel syndrome (CTS).[1] It is a compression to the median nerve that characterized generally by different symptoms such as pain, numbness, and paresthesia. These symptoms occur in the area supplied by the median nerve such as thumb, index, and middle fingers, in addition to the lateral half of the ring finger.[2] The main cause of this syndrome is unknown, but it could be a consequences of median nerve vein circulatory disorder and increasing internal canal pressure which indeed results in ischemia to the median nerve. Moreover, it may take place due to tenosynovitis of the tendons that close to the median nerve. [3] In addition, wrist bone fracture or dislocation, connective tissue disorder, obesity, pregnancy, infections, and metabolic disease may also lead to this syndrome.[2]

However, among the general population, the prevalence of CTS are ranged between $3 \%$ and $6 \%$, $[4]$ while among pregnant women it reaches $19 \%,[5]$ whereas among diabetic patients it reaches up to $20 \%$. [6] The working population has showed more prevalence of this syndrome than the non-working population. Occupationally, this syndrome happens frequently with the jobs that include chronic bending movements of the wrist during forceful catch-

*Corresponding Author:

Abdelmonem Ali Abdelnabi,

Assistant lecturer at Preventive and community dentistry Department, Head of child dental care department at Libyan International Medical University, Libya

Tel: 00218927980791

E-mail: Abdelmonem.ast@gmail.com/Abdelmonem@limu.edu.ly

Received: June 22, 2021

Accepted: November 07, 2021

Published: November 10, 202

Citation: Abdelmonem Ali Abdelnabi, Rafeeq Mohammed Al Kuwafi, Khadeejah Abdulsalam Hashim, Marwa Ahmed Bugedar. Prevalence of Carpal Tunnel Syndrome Symptoms Among Dentists in Benghazi City - Libya Int J Dentistry Oral Sci. 2021;8(11):4939-4942. doi: http://dx.doi.org/10.19070/2377-8075-21000998

Copyright: Abdelmonem Ali Abdelnabi 2021 . This is an open-access article distributed under the terms of the Creative Commons Attribution License, which permits unrestricted use, distribution and reproduction in any medium, provided the original author and source are credited. 
ing of devices. [4] Practicing dentistry is one of these jobs, which include repetitive twisting of the wrist especially during manual dental root canal treatment, scaling, tooth preparation, and extraction. Among dental practitioners, the commonness of CTS symptoms in Karachi city of Pakistan, is 10.31\%,[7] while in Riyadh city of Saudi Arabia it almost 30.5\%.[4] In Libya, the prevalence of this syndrome among dental practitioners has not yet been known. Therefore, the aim of this study is to demonstrate the prevalence of CTS symptoms among dentists who work in Benghazi.

\section{Material And Methods}

A cross-sectional study was conducted in Benghazi - Libya in 2019. A total of 205 dentists from 14 different polyclinics and private dental clinics were included. Those participants were asked to answer a questionnaire regarding CTS.

A two parts of self-administrated questionnaire was used. The socio-demographic data was included in the first part of the questionnaire, which include questions related to age, gender, years of experience, degree level, specialty, working time and medical condition. The second part of the questionnaire include nine different questions related to the symptoms of CTS and its severityas seen in Table 1. All data were analyzed by using IBM SPSS software version 22

\section{Results}

Out of 205 questioners were distributed, only 132 dentists (64.4 $\%)$ responded, with a dropout rate of 73 dentists (35.6\%). Regarding gender, 73 dentists $(55.3 \%)$ were male and 59 dentists $(44.7 \%)$ were female (Figure 1$)$. The highest number of participants 45 dentists $(34.1 \%)$ was in the age group $30-34$ years old and 44 dentists $(33.3 \%)$ was in the age group less than 30 years old, whereas the lowest number of participants 3 dentists $(2.3 \%)$ was in the age group $40-44$ years old (Table 2). 52 dentists (39.4\%) have less than five years work experience, while 35 dentists $(26.5 \%)$ have an 5-to-10 work experience. Moreover, 26 dentists $(19.7 \%)$ and 19 dentists $(14.4 \%)$ were reported to have 10 to 15 years of experience and $\geq 15$ years of experience respectively. Regarding medical condition of participants, 5 dentists $(3.8 \%)$ were reported to have type II diabetes mellitus, 2 dentists $(1.5 \%)$ have hypothyroidism and 2 dentists $(1.5 \%)$ have hypertension. However, no one seemed to suffer from rheumatoid arthritis or other joint diseases. In relation to pregnancy, only 3 dentists $(2.3 \%)$ were pregnant.

It was found that 94 dentists $(71.2 \%)$ of the participants were graduated dentists, 31 dentists $(23.5 \%)$ have master degree and only 7 dentists $(5.3 \%)$ have a $\mathrm{PhD}$ degree. The highest percentage of the participants 93 dentists $(70.5 \%)$ work as a general dental practitioner (GDP), while the other participants were distributed among other work specialties (Table 3).

It was found that 32 dentists $(24.2 \%)$ of the total participants experienced hand or wrist pain at night, in which the severity of the pain was distributed into 19 dentists (59.4\%), 12 dentists (37.5\%), and 1 dentists $(3.1 \%)$ for mild, moderate and severe pain respectively. Nevertheless, the percentage of dentists' ages who complained about hand or wrist pain at daytime were more than that at night with 42 dentists $(31.8 \%)$ and 32 dentists (24.2\%). Some of them 27 dentists $(64.3 \%)$ complained about mild pain and 15 dentists $(35.7 \%)$ had moderate pain, while there was no severe pain reported meanwhile during daytime. In addition, 19 dentists $(14.4 \%)$ of the total participants showed that they suffered from numbness that were classified into $36.8 \%$ for mild, $57.9 \%$ for moderate, and $5.3 \%$ for severe form of hand numbness.

Moreover, 34 dentists (25.8\%) were reported the symptom of hand weakness during work. The majority of them 24 dentists

Figure 1. Gender distribution.

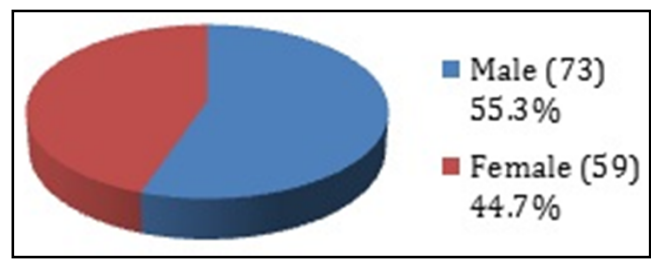

Table 1. The CTS symptoms for a typical twenty-four hour period during the past three months (mark one answer to each question).

\begin{tabular}{|c|c|c|c|c|c|c|}
\hline & \multirow{2}{*}{ QUESTION } & \multirow{2}{*}{ Yes } & \multirow{2}{*}{ No } & \multicolumn{3}{|c|}{ If yes, is it } \\
\hline & & & & mild & Moderate & Sever \\
\hline 1 & Do you havehand or wrist pain at night? & & & & & \\
\hline 2 & Do you typically have pain in your hand or wrist during the daytime? & & & & & \\
\hline 3 & Do you have numbness (loss of sensation) in your hand? & & & & & \\
\hline 4 & Do you have weakness in your hand or wrist? & & & & & \\
\hline 5 & Do you have tingling sensations (jخ)in your hand? & & & & & \\
\hline 6 & $\begin{array}{l}\text { Do you have difficulty with the grasping and use of small objects such as end- } \\
\text { odonticfiles? }\end{array}$ & & & & & \\
\hline 7 & $\begin{array}{l}\text { Do you have difficulty with the grasping of manual instruments such as (excava- } \\
\text { tor ,carver or manual scaling instrument) ? }\end{array}$ & & & & & \\
\hline 8 & Do you have difficulty with the grasping surgical forceps during dental extraction? & & & & & \\
\hline 9 & Do you have difficulty with grasping of dental hand piece? & & & & & \\
\hline
\end{tabular}


Table 2. Age distribution.

\begin{tabular}{|c|c|c|}
\hline Age & Frequency & Percent \\
\hline less than 30 & 44 & 33.3 \\
\hline $30-34$ & 45 & 34.1 \\
\hline $35-39$ & 25 & 18.9 \\
\hline $40-44$ & 3 & 2.3 \\
\hline $45-49$ & 4 & 3 \\
\hline $50+$ & 11 & 8.3 \\
\hline Total & 132 & 100 \\
\hline
\end{tabular}

Table 3. The distribution of work specialties.

\begin{tabular}{|c|c|c|}
\hline Specialty & Frequency & Percentage \\
\hline Dental anatomy & 1 & 0.8 \\
\hline Endodontic & 5 & 3.8 \\
\hline Aesthetic & 2 & 1.5 \\
\hline Fixed prosthodotic & 3 & 2.4 \\
\hline GDP & 93 & 70.5 \\
\hline Oral surgery \&Implant & 5 & 3.8 \\
\hline Restorative Dentistry & 6 & 4.6 \\
\hline Oral medicine & 3 & 2.3 \\
\hline Oral pathology & 1 & 0.8 \\
\hline Orthodontic & 3 & 2.3 \\
\hline Pedodontic & 5 & 3.8 \\
\hline Periodontic & 3 & 2.3 \\
\hline Removable prosthodotic & 2 & 1.6 \\
\hline Total & 132 & 100 \\
\hline
\end{tabular}

Table 4. Numbers and severity of CTS symptoms.

\begin{tabular}{|c|c|c|c|c|}
\hline & Total & Mild & Moderate & Sever \\
\hline Symptom & No. $(\%)$ & No. $(\%)$ & No. $(\%)$ & No. $(\%)$ \\
\hline Hand or wrist pain at night & $32(24.2 \%)$ & $19(59.4 \%)$ & $12(37.5 \%)$ & $1(3.1 \%)$ \\
\hline Hand or wrist pain at daytime & $42(31.8 \%)$ & $27(64.3 \%)$ & $15(35.7 \%)$ & $0(0 \%)$ \\
\hline Hand numbness & $19(14.4 \%)$ & $7(36.8 \%)$ & $11(57.9 \%)$ & $1(5.3 \%)$ \\
\hline Hand weakness during work & $34(25.8 \%)$ & $24(70.6 \%)$ & $9(26.50 \%)$ & $1(2.9 \%)$ \\
\hline Hand tingling & $23(17.4 \%)$ & $13(56.5 \%)$ & $9(39.10 \%)$ & $1(4.3 \%)$ \\
\hline Difficulty in grasping and usage of small objects & $19(14.4 \%)$ & $11(57.9 \%)$ & $7(36.80 \%)$ & $1(5.30 \%)$ \\
\hline Difficulty in handling of manual instrument & $12(9.1 \%)$ & $7(58.3 \%)$ & $4(33.30 \%)$ & $1(8.30 \%)$ \\
\hline Difficulty in handling of surgical forceps & $37(28 \%)$ & $24(64.9 \%)$ & $12(32.4 \%)$ & $1(2.7 \%)$ \\
\hline
\end{tabular}

$(70.6 \%)$ were reported with mild form of hand weakness. Moreover, the hand tingling was reported by 23 dentists (17.4\%) (Table $4)$.

However, 19 dentists (14.4\%) reported to have the difficulty with grasping and handling of small objects. Finally, the difficulty in handling of manual instruments and surgical forceps recorded by 12 dentists $(9.1 \%)$ and 37 dentists (28\%) respectively (Table 4).

\section{Discussion}

This cross sectional study evaluated the median nerve neuropathy among 132 dentists with different ages, years of working experience and work specialities.

Occupational musculo-skeletal complains in dentistry usually occurs with upper body movements in sitting or standing positions during dental work. $[8,9]$

A considerable proportion of the participants 81 dentists $(61.3$ $\%$ ) had one or more symptoms of CTS. This was much higher than other studies with similar aim like Karachi study (10.3\%),[7] Riyadh study (30.5\%),[4] Isfahanian study (16.7\%),[2] Shiraz study (17.5\%),[10] Chennai study (25.7\%),[11] United States army 
dentists study(28\%),[12] Australian study (34\%).[13] Malaysian study 21.2\%, [14] and Lahore study (15.5\%).[15] The explanation of this could be due to lack of knowledge about CTS and how it could be prevented as CTS was not taught during undergraduate and even in postgraduate years, also considerable proportion of the participants 60 dentists $(45.5 \%)$ were working full time which can attribute to development of CTS.

60 dentists $(75 \%)$ with CTS symptoms were working as general dental practitioner (GDP) and that can explained by the large number of GDP participants in this study. In regarding to dental speciality and CTS, it was found that 4 endodontists (80\%), 3 periodontists $(100 \%), 3$ pedodontists $(60 \%)$ and 4 restorative dentists $(66.6 \%)$ had CTS symptoms, similar results were found in other studies like Karachi study, [7] Riyadh study, [4] and Chennai study. [11] Gender distribution of dentists with symptoms of CTS was 43 female dentist (53\%) and 38 male dentist (47\%). Female dentist was slightly found to be more prone to CTS than male dentist and this tendency could be due to smaller wrists and potentially smaller carpel tunnel volume.[16]

Unlike other studies, [17] the symptoms of pain related to CTS were more during daytime than that of nighttimes, the explanation of that could be attributed to rest movement during dental work which increases the compression of the median nerve as it passes through the carpal tunnel.

\section{Conclusion}

This study shows a significant number of dentists who may havea Carpal Tunnel Syndrome in the city of Benghazi. General dental practitioners, endodontists, periodontists and pedodontist are more prone to CTS. It is, therefore, important to draw a serious attention to CTS and its risk factors. In addition, to increase the awareness and knowledge about CTS among dental students and working dentists. Further studies include larger sample size and more different cities across Libya should be conducted.

\section{Clinical Significance}

This paper demonstrates the relationship of Carpal tunnel syndrome among dentists as an occupation that requires wrist movement and bending which is a significant cause of the syndrome.

\section{References}

[1]. Aroori S, Spence RA. Carpal tunnel syndrome. Ulster Med J. 2008 Jan;77(1):6-17. PubMed PMID: 18269111.

[2]. Haghighat A, Khosrawi S, Kelishadi A, Sajadieh S, Badrian H. Prevalence of clinical findings of carpal tunnel syndrome in Isfahanian dentists. Adv Biomed Res. 2012;1:13. PubMed PMID: 23210072.

[3]. Bland JD. Carpal tunnel syndrome. BMJ. 2007 Aug 18;335(7615):343-6. PubMed PMID: 17703044.

[4]. Alhusain FA, Almohrij M, Althukeir F, Alshater A, Alghamdi B, Masuadi E, Basudan A. Prevalence of carpal tunnel syndrome symptoms among dentists working in Riyadh. Ann Saudi Med. 2019 Mar-Apr;39(2):104-111. PubMed PMID: 30905925.

[5]. Khosrawi S, Maghrouri R. The prevalence and severity of carpal tunnel syndrome during pregnancy. Adv Biomed Res. 2012;1:43. PubMed PMID: 23326774.

[6]. Oktayoglu P, Nas K, Kilinç F, Tasdemir N, Bozkurt M, Yildiz I. Assessment of the Presence of Carpal Tunnel Syndrome in Patients with Diabetes Mellitus, Hypothyroidism and Acromegaly. J ClinDiagn Res. 2015 Jun;9(6):OC14-8. PubMed PMID: 26266148.

[7]. Ahmed A, Khan A, Siddiqui Z, AHMED MR, Askari H, Zahid A. Prevalence of carpel tunnel syndrome in the dentists working in Karachi. Pakistan Oral \& Dental Journal. 2014 Dec 1;34(4).

[8]. Chin DH, Jones NF. Repetitive motion hand disorders. J Calif Dent Assoc. 2002 Feb;30(2):149-60. PubMed PMID: 11883427.

[9]. Brown PN. What's ailing us? Prevalence and type of long-term disabilities among an insured cohort of orthodontists. Am J OrthodDentofacialOrthop. 2004 Jan;125(1):3-7. PubMed PMID: 14718873.

[10]. BorhanHaghighi A, Khosropanah H, Vahidnia F, Esmailzadeh S, Emami Z. Association of dental practice as a risk factor in the development of carpal tunnel syndrome. J Dent (Shiraz). 2013 Mar;14(1):37-40. PubMed PMID: 24724115.

[11]. Inbasekaran D, Sankari M, Nambi SG. Prevalence of carpal tunnel syndrome among dentists in Chennai, India. Drug Invention Today. $2018 \mathrm{Nov}$ 2;10(3):3262-5.

[12]. Lalumandier JA, McPhee SD. Prevalence and risk factors of hand problems and carpal tunnel syndrome among dental hygienists. J Dent Hyg. PubMed PMID: 11475758.

[13]. Leggat PA, Kedjarune U, Smith DR. Occupational health problems in modern dentistry: a review. Ind Health. 2007 Oct;45(5):611-21. PubMed PMID: 18057804.

[14]. Munirah MA, Normastura AR, Azizah Y, Aziah D. Prevalence of probable carpal tunnel syndrome and its associated factors among dentists in Kelantan. International Journal of Collaborative Research on Internal Medicine \& Public Health. 2014;6(8).

[15]. Ehsan M, Ehsan S, Arshad H. Frequency of carpal tunnel syndrome in dentists working in government hospitals of lahore. Int J Sci Res. 2013;14:23197064.

[16]. SayeghGhoussoub M, Ghoussoub K, Moucharrafieh L, Khoury A, Sleilaty G, Rifä̈ K. Troubles musculo-squelettiques chez une population de chirurgiens-dentisteslibanais: Fréquence et facteurs de risque [Musculo-skeletal problems among Lebanese dental surgeons. Occurrence and risk factors]. J Med Liban. 2005 Jan-Mar;53(1):21-7. PubMed PMID: 16398209.

[17]. Šošić L, Bojnec V, Lonzarić D, JesenšekPapež B. An advanced stage of carpal tunnel syndrome - is night-time splinting still effective? Int J Occup Med Environ Health. 2020 Oct 20;33(6):771-780. PubMed PMID: 32929289. 